MAGALHÃES, Marionilde Brepohl de. Pangermanismo e nazismo: a trajetória alemã rumo ao Brasil. Campinas : Editora da UNICAMP/FAPESP, 1998.

\title{
TRAÇOS DO BRASIL
}

\author{
Tiago Losso \\ Universidade Estadual de Campinas
}

O tema da identidade nacional é recorrente em grande parte da produção intelectual brasileira. Silvio Romero (ainda no século XIX), Alberto Torres, grande parcela da intelectualidade da década de 1930 — de um Oliveira Vianna a um Gilberto Freire - , e mesmo pensadores já vinculados à produção acadêmica universitária se ocuparam, com distintas ênfases e interesses, em mapear e analisar os componentes do caráter nacional brasileiro (cf. LEITE, 1983).

Marionilde Brepohl de Magalhães pretende, em Pangermanismo e nazismo, concatenar dados para a compreensão de um elemento fulcral do processo de construção da identidade brasileira: os imigrantes alemães. Questão latente em especial no sul do Brasil, o teuto-brasileiro ${ }^{1}$ passou por diversos "locais" nesta identidade. Foi perigoso, uma ameaça ao País, e finalmente símbolo de um País construído pelo labor e disposição de imigrantes dispostos a formar aqui uma nova "pátria”.

O objetivo desta resenha é justamente mostrar como a obra em questão colabora para matizar e melhor compreender a forma como estes imigrantes se inserem na realidade brasileira. Mais importante do que imaginar como os "brasileiros" os viram, o livro de Magalhães nos auxilia a entender de que forma os "alemães" se compreenderam no Brasil.

Estruturada em três partes, a obra ocupa-se em relacionar pangermanismo, nazismo e protestantismo, na tentativa de elucidar de que forma a inserção do grupo teuto se deu na realidade brasileira. Assim, na primeira parte, através do estudo do discurso jornalístico ligado aos teutos, a autora procura compreender a emergência da "cultura germânica" no sul do Brasil. Cabe aqui salientar alguns pontos de referência sobre a forma específica com que os descendentes de alemães compreendem sua relação com a pátria e com o Estado. Giralda Seyferth mostra isso de forma exemplar, ao estudar uma comunidade teuta em Santa Catarina. Segundo a autora, não é estranho aos olhos dos alemães e descendentes ter, concomitantemente, lealdade a dois países distintos. Com termos e valores diferentes, este grupo social estabelece relações com sua pátria de origem, ligada a seu sangue — a Alemanha — , e uma nova pátria, que ocupa um lugar diferente em sua teia de significados sociais e culturais, justamente por ser o local geograficamente demarcado que os acolhe em dado momento - o Brasil. Os significados dos termos Estado — referente ao país onde se vive —, e pátria — concernente ao local de "origem" — marcam bem esta peculiaridade ${ }^{2}$.

Compreende-se assim, como então procura demonstrar Magalhães, a possibilidade que se abre para o surgimento e a fomentação de todo um discurso e de uma visão de mundo que pretende manter os descendentes de alemães continuamente ligados à cultura e ao mundo de seus antepassados. E a autora de Pangermanismo e nazismo o faz de forma especialmente clara e coerente, ressaltando inclusive um ponto extremamente complexo e ambíguo deste assunto: o medo e, ao mesmo tempo, a admiração pelos teutos. Os descendentes de outras etnias (portuguesa, por exemplo) viam nessa ligação com a pátria alemã um perigo,

1 Termo utilizado para designar o indivíduo de origem alemã.

2 Essa passagem indica de forma mais detalhada a argumentação da autora: "A economia pode ser brasileira, a política também: mas a filiação étnica do teuto-brasileiro é com o povo alemão - são diferentes dos outros brasileiros, formam um grupo separado com instituições que lhes são específicas e permitem identificá-los [...] Elas [as instituições do grupo referido] são teuto-brasileiras, e é por isso que estou falando em grupo étnico teuto-brasileiro, cuja comunidade se compõe de instituições que seus membros julgam ser caracteristicamente alemãs" (SEYFERTH, 1981, p. 154). 
uma possibilidade de interferência deste país na realidade brasileira. Simultaneamente, estas mesmas populações eram alvo de admiração, sendo identificados como 'trabalhadores', 'brancos' e 'disciplinados', algo que perfeitamente se adequava ao discurso eugenista característico da década de $1930^{3}$.

Num segundo momento, Brepohl Magalhães desdobra sua investigação sobre o pangermanismo, já ligando este aspecto de seu estudo com um novo foco de atenção: o nacional-socialismo alemão. A autora mostra, assim, que a propaganda nacional-socialista encontra um terreno fértil, preparado pelo germanismo, para obter simpatizantes e militantes entre os brasileiros descendentes de alemães. No entanto, devemos ter alguns cuidados com esta assertiva. Como a própria autora faz questão de mostrar, existem limites muito claros entre as intenções dos membros nacional-socialistas e a verdadeira dimensão da empolgação dos teutos com este credo político. Mais uma vez mostra-se eficaz a primeira parte do livro. A propalada simpatia dos teutos para com o nazismo está muito ligada, antes de tudo, com a suposta era de prosperidade emergente na Alemanha de Hitler. Vai uma longa distância em simplesmente identificar isto com pretensões de qualquer outro tipo, inclusive com o medo de que os "alemães" do sul do Brasil criassem uma Alemanha subtropical $^{4}$. Em termos resumidos, a autora mostra que havia limites a esta simpatia e que nunca houve algum tipo de ação coordenada e abrangente que pretendesse de alguma forma tornar factível a tese da "invasão alemã". Cabe ainda lembrar da simpatia despertada em grandes figuras do governo federal em relação a Alemanha nazista, e a tardia opção do governo brasileiro pelos aliados no momento de marcar posição na II Guerra Mundial. Em nenhum momento se acusou Getúlio Vargas de nazista, pelo menos não nos termos que o Capitão Lara Ribas acusa os teuto-brasileiros ${ }^{5}$.

A última parte do livro de Magalhães se debruça sobre a terceira dimensão de sua estrutura argumentativa: o protestantismo, ligando-o aos dois assuntos anteriores. Neste momento, a autora assume uma nova postura metodológica, como já é avisado na introdução do trabalho. Passa a estudar especificamente a inserção de um pastor alemão que chega ao Brasil, traçando suas ações desde a formação familiar na Alemanha até sua participação em periódicos brasileiros, como formador de opinião, tendo a colônia de imigrantes alemães como alvo de seu discurso. A autora tem acesso a todo o arquivo pessoal deste pastor, e usa com maestria estes dados.

Se nas duas partes iniciais do texto a abordagem privilegia uma gama variada de fontes - desde bibliográficas, passando por documentos primários, até o uso de periódicos e publicações da época - ao utilizar aqui uma única "fonte", perde-se o caráter "multifacetado" de sua argumentação. Claramente é objetivo da autora articular em um caso específico as argumentações anteriormente construídas, mas isto não fica suficientemente bem realizado. Ao deter-se de forma tão minuciosa na inserção intelectual de um 'germanista', para usar as expressões da autora, o pastor Friedrich Wilhelm Brepohl, na realidade brasileira, Magalhães acena com elementos que não se justificam por si mesmos, caso o leitor queira interligá-los com o conjunto do texto. Se escolhesse fazer por sua própria conta esta ligação, a autora teria que ser mais incisiva, como o foi nas partes anteriores do livro. Ressalte-se aqui que de forma alguma esta observação tira os méritos do livro, estes sim múltiplos, mas impede que se obtenha, possivelmente, o final mais adequado para uma obra tão instigante.

Uma bibliografia considerável se preocupa com as questões dos imigrantes no Brasil, e foge aos propósitos desta resenha arrolar essas interpretações. Mais especificamente, essa bibliografia muitas vezes é de caráter regional, e não chega a tornar-se leitura de muitos. No entanto, cabe aqui assinalar duas obras que, numa análise regional, universalizam o tema dos grupos colonizadores do sul do Brasil, colaborando para uma

\footnotetext{
3 Para este último ponto, cf. a p. 43 da obra de Magalhães, onde a autora cita Alcir Lenharo (1987). Este último aborda o discurso político e social da década de 1930, no qual o "problema" alemão emerge com insuspeitada força.

4 Este medo existiu, e foi inclusive alvo de análise de um livro intitulado O punhal nazista no caracão do Brasil, onde um delegado de polícia pretendeu mostrar como existiu um plano de invasão alemão, contando com a colaboração dos teutobrasileiros. Cf. RIBAS, 1945. Ainda sobre a possibilidade de uma invasão alemã no Brasil, René G ertz afirma que não existiram planos concretos de Hitler ou do Reich para a invasão de alguma área da América Latina. Não é plausível, inclusive, que os altos escalões do nazismo alemão tivessem efetivado alguma ação, ou mesmo pensado em alguma, com o objetivo de efetivar algo neste sentido. Cf. GERTZ, 1987, p. 75-80.

5 Podemos ainda salientar que o grupo nazista organizado em Joinville (SC) possuía apenas 22 membros na década de 1930. Cf. GERTZ, 1987, p. 84.
} 
compreensão da realidade nacional.

Giralda Seyferth, em Nacionalismo e identidade étnica, e René Gertz, em O fascismo no sul do Brasil, merecem destaque. Mesmo não tratando especificamente da colonização européia do sul do Brasil, Gertz, ao estudar o fenômeno integralista, toca, como não poderia deixar de ser, no caso dos descendentes de italianos e alemães. Num momento de exacerbação de nacionalismos, aqui e na Europa, obviamente o envolvimento de grupos identificados, à época, com o fascismo italiano e com o nazismo alemão, em um movimento de caráter autoritário e mobilizador como o integralismo, gerou uma série de mal-entendidos, violências e intolerâncias. Gertz busca oferecer uma alternativa aos esquemas analíticos que procuraram compreender a participação dos descendentes de alemães e italianos no integralismo como uma mera transposição das idéias fascistas e nazistas para o Brasil. Comparando a realidade do Rio Grande do Sul e de Santa Catarina, Gertz explica este fenômeno num registro político e sociológico, e não étnico.

A estruturação da política partidária nestes dois estados do Sul é parte da argumentação de Gertz. No Rio Grande do Sul, afirma o autor, o comando político estava nas mãos de uma oligarquia que temia e controlava as populações teutas, e estas, por não vislumbrarem uma participação efetiva no poder, aderiam ao governo estadual. Já no caso catarinense, os teutos participavam de forma diferente da política, sendo que o poder não estava concentrado nas mãos de uma única oligarquia, mas sim de duas (os Ramos e os Konder Bornhausen).

Após 1930 ascende ao poder estadual catarinense a família Ramos, que trata com animosidade os teutos, efetivando ações que visavam prejudicar estas populações. O integralismo surge, no caso catarinense, muito mais em função de uma possibilidade de participação política autônoma em relação às oligarquias, do que necessariamente como um reflexo de simpatias pelo nazismo. É assim que o autor compreende a maior abrangência do movimento integralista em Santa Catarina, se comparado ao caso do Rio Grande do Sul.

René Gertz busca demonstrar que, ao participar do integralismo, o descendente de alemães estava muito mais preocupado em estabelecer um canal de participação política, do que construir por aqui uma nova Alemanha.

Giralda Seyferth, por sua vez, elabora uma interessante interpretação sobre a comunidade descendente de alemães em Santa Catarina. Esta autora procura demonstrar que as tentativas dos teutos em se manterem ligados à Alemanha é muito mais uma forma destes grupos forjarem uma identidade própria, do que uma afronta ao Brasil. Como já foi anteriormente mencionado, aos olhos de um filho ou neto de alemães, nada mais normal que sentir-se alemão sem ofender ou desrespeitar o Brasil. Tratando do pangermanismo, Seyferth mostra que esta idéia liga a nacionalidade alemã a uma herança de sangue, possibilitando que um descendente de alemães sinta-se alemão em qualquer Estado onde viva, sem se sentir traidor deste Estado. Indo mais adiante, encontraremos uma explicação mais acurada para esta situação. Seyferth aponta a diferença entre os significados de nação e cidadania entre os teutos. O primeiro termo está ligado a um povo, a um conjunto de traços que identificam determinados indivíduos, traços estes herdados, enquanto o termo cidadania concerne à ligação política do indivíduo a um Estado.

Assim, a leitura conjunta dos livros de Seyferth, Magalhães e Gertz conduzem a um olhar um tanto quanto matizado do "problema alemão" no Brasil.

Ao agregarmos as análises de Seyferth e Magalhães, teremos três pontos básicos de análise. Um primeiro diz respeito à visão de mundo dos teutos, e sua relação, por vezes incompreensível aos olhos de outras etnias, entre a Alemanha e o Brasil. Em seguida, podemos atentar para a necessidade destes grupos manterem laços com a Alemanha, e somente desta forma construir uma idéia de pertencimento a algo abstrato como uma comunidade, parar usar os termos de Benedict Anderson (1988). Por fim, observe-se a angústia constante destes grupos de imigrantes e descendentes em serem aceitos no Brasil, através de uma inserção que respeite a alteridade oriunda de sua forma de ver o mundo. Com estas três sugestões, compreendemos mais claramente o quanto conflituosa foi a inserção dos imigrantes alemães no Brasil.

Pangermanismo e nazismo surge para agregar mais dados, visões e interpretações sobre a "formação do Brasil", algo que se pode considerar, já no limiar do novo século, como algo inacabado e pleno de conflitos se é que algum processo delicado como a formação de um país pode ser considerado, em algum momento, de forma estanque e acabada. A obra de Marionilde Brepohl de Magalhães ocupa, então, um lugar nas referências bibliográficas necessárias para estudo e compreensão desta dimensão da realidade brasileira.

Quando assistimos a campanhas institucionais que querem convencer que o Brasil "nasce” em 1500 , com 
data e local identificáveis, mostra-se muito mais pertinente uma cuidadosa reflexão sobre o que é o Brasil, ou sobre seu caráter nacional — para voltar ao início desta resenha. Se o Brasil "nasce" em algum momento, este momento não é unívoco. Uma multiplicidade de processos deve ser levada em conta para estabelecer este nascimento, e compreender os grupos imigrantes que formam sua população é um dos mais férteis. Os descendentes de alemães formam uma parcela do Brasil. Sua identidade, sua inserção no Brasil, e os conflitos que cercam este evento ainda estão longe de terem sido eficientemente estudados. É trabalho ainda a ser feito.

Recebido para publicação em agosto de 1999.

Tiago Losso (tiagolosso @ bol.com.br) é Licenciado em História pela Universidade do Estado de Santa Catarina (UDESC), Bacharel em Ciências Sociais pela Universidade Federal de Santa Catarina (UFSC) e Mestrando em Ciência Política na Universidade Estadual de Campinas (UNICAMP).

\section{REFERÊNCIAS BIBLIOGRÁFICAS}

ANDERSON, B. 1988. Nação e consciência nacional. São Paulo : Ática.

GERTZ, R. 1987. O fascismo no sul do Brasil. Porto Alegre : Mercado Aberto.

LEITE, D. 1983. O caráter nacional brasileiro: história de uma ideologia. São Paulo : Pioneira.

LENHARO, A. 1987. A sacralização da política. Campinas : Papirus.

RIBAS, A. de L. 1945. O punhal nazista no coração do Brasil. s.l. : s.ed.

SEYFERTH, G. 1981. Nacionalismo e identidade étnica. Florianópolis : FCC. 